\title{
03 RISK OF INJURIOUS ROAD TRAFFIC CRASH AFTER PRESCRIPTION OF ANTIDEPRESSANTS
}

doi:10.1136/injuryprev-2012-040590r.3

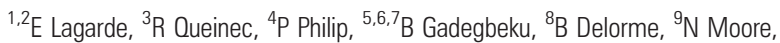
${ }^{10} \mathrm{~S}$ Suissa, ${ }^{1,2,11} \mathrm{~L}-\mathrm{R}$ Salmi, ${ }^{1,2} \mathrm{~L}$ Orriols, on behalf of the CESIR research group. ${ }^{1}$ University of Bordeaux, ISPED, INSERM U897 Research Centre 'Epidemiology and Biostatistics', Bordeaux, France; ' $I N S E R M$, ISPED, Injury Prevention and Control Research Team, INSERM U897, Bordeaux, France; ${ }^{3}$ Pôle Entre-Deux-Mers, CH, Cadillac, France; ${ }^{4}$ USR CNRS SANPSY 3413, University of Bordeaux, Bordeaux, France; ${ }^{5}$ University of Lyon, Lyon, France; ${ }^{6}$ IFSTTAR, UMR T 9405, UMRESTTE, Bron, France; 'University of Lyon 1, UMRESTTE, Lyon, France; ${ }^{8}$ Service de l'Évaluation de la Surveillance du Risque et de I'Information sur le Médicament, AFSSAPS, Saint-Denis, France; ${ }^{9}$ INSERM U657, CICP0005, Pharmacology, University of Bordeaux, Bordeaux, France; ${ }^{10}$ Department of Epidemiology and Biostatistics, Centre for Clinical Epidemiology, McGill University, Montreal, Quebec, Canada; ${ }^{11}$ University Hospital Pellegrin, Bordeaux, France
\end{abstract}

Background Antidepressants are commonly used worldwide. Experimental studies have suggested that antidepressants may impair driving abilities.

Aims/Objectives/Purpose The study aims to estimate the risk of road traffic crash associated with prescription of antidepressants.

Methods Data from three French national databases were extracted and matched: the national health care insurance database, police reports, and the national police database of injurious crashes. A case-control analysis comparing 34896 responsible versus 37789 non-responsible drivers was conducted. Casecrossover analysis was performed to investigate the acute effect of medicine exposure.

Results/Outcomes 72685 drivers identified by their national healthcare number, involved in an injurious crash in France over the July 2005 to May 2008 period, were included. 2936 drivers (4.0\%) were exposed to at least one antidepressant on the day of the crash. The results showed a significant association between the risk of being responsible for a crash and prescription of antidepressants $(\mathrm{OR}=1.34$ (1.22 to 1.47$))$. The case-crossover analysis showed no association with treatment prescription but the risk of road traffic crash increased after an initiation of an antidepressant treatment $(\mathrm{OR}=1.49$ (1.24 to 1.79$))$ and after a change in antidepressant treatment $(\mathrm{OR}=1.32$ (1.09 to 1.60$))$.

Significance/Contribution to the Field Patients and prescribers should be warned about the risk of crash during periods of antidepressant medication and particularly high vulnerability periods such as those when a treatment is initiated or modified. 